\title{
Exploring Orientation Cues in both Digital and Physical Books
}

\author{
Nicholas Vanderschantz, Claire Timpany, Annika Hinze, Yuchen Du \\ Department of Computer Science \\ The University of Waikato, New Zealand \\ \{vtwoz, timpany, hinze\}@waikato.ac.nz,yd76@students.waikato.ac.nz
}

\begin{abstract}
Electronic books (eBooks) and eReaders are now a commonplace tool in the reading experience for many readers. Yet these have long received mixed reviews. Designing suitable interactions that support successful eReading experiences is a relevant task. This paper reports on an exploration of orientation cue designs for electronic books through consideration of design techniques implemented in both physical books (pBooks) and eBooks. We executed a case study of contemporary pBook and eBook orientation cue designs and report on the results of a heuristic evaluation with a small set of expert evaluators. Our findings identify the need for further investigation of the design of orientation cues for both pBooks and eBooks.
\end{abstract}

eBooks, eReading, navigation, orientation

\section{INTRODUCTION}

eBooks and eReaders have long received mixed review. Some critics consider that reading on a screen has several limitations, which creates an unpleasant reading experience, and therefore traditional physical books (pBooks) will not be replaced. On the contrary, others report that eBooks represent the future of reading with the extinction of traditional physical books being imminent. These arguments aside, eBooks have been a part of the book world for some time now and do not appear to be diminishing in uptake for many reading situations. The form and features of a physical book are familiar to readers and require little cognitive load to navigate the book nor for the reader to orientate themselves within the text. However, the cues for navigation and orientation in digital books are less familiar for the majority of readers and conventions are not as well established. Therefore, we hypothesise that an integral research avenue is the investigation of how best to implement orientation cues (see Section 2) in eBooks for readers. This paper presents our exploratory investigations into the current state of orientation in reading and highlights the areas of need for deeper investigation.

The remainder of this paper is structured as follows: Section 2 provides a background to orientation cues while Section 3 introduces a survey of the related work. Section 4 outlines a visual audit of four books in both print and digital formats revealing the design conventions and orientation cues used. Section 5 describes the design and the expert user review of six prototype designs ( 3 pBook \& 3 eBook). Sections $6 \& 7$ discuss the implications of our findings.

\section{ORIENTATION CUES IN READING}

Orientation is a process of people confirming their exact or relative position in a space or their direction to somewhere. Orientation cues refer to the signs and symbols (Bernstein 1988) that enable people to distinguish where they are in a space or in this context, in a book. These so-called orientation cues in books are clues and cues that can assist readers to distinguish their current position (i.e. current page) and inform reading progress through the book (i.e. how far through a book they are) (Marshall2009).

In this research, the orientation cues that we identify in eBooks are page numbers, running headers, running footers, chapter headings, bookmarks, percentage or progress indicators, and the physical object. Briefly, page numbers are a common tool for identifying the present page in a book, running headers and footers often indicate either the chapter or book name, and chapter headings are used at the start of a new chapter, perhaps on a title page or simply as part of the run of text. Bookmarks in pBooks have been described as any number of physical devices, including a piece of paper, a finger placed between pages, or a folded corner to 
help a user re-locate a position in a book. Similarly, bookmarks in eBooks are a digital equivalent for marking a page to return to. Percentage and progress indicators are a digital representation not found in pBooks which show either progress in the current chapter or progress through the entire book and can be seen represented as dots, lines, and bars. The final cue we note here is that of the physical object, which is the term Wilson used to describe the action of readers reviewing present location in a book by comparing the amount of a book that has been read, and the remaining pages they are yet to read in order to determine their relative location in the book (Wilson et al. 2002).

It must be noted that orientation differs from navigation. When reading a book, navigation is a process of a reader locating the specific information. Therefore, navigation cues refer to the cues that assist a reader to find the specific information they are seeking. Marshall gives the analogy that navigation cues are akin to the number buttons in the elevator; when a person wants to go to the sixth floor, she just needs to press the 6 button (Marshall 2009). In pBooks, there are several elements that constitute the navigation mechanism. These include tables of contents (ToC), indexes, bookmarks, tabs, lists of illustrations and figures. The navigation cues we identify in pBooks and eBooks are ToCs, indexes, search buttons, hypertext, bookmarks, tabs, lists of illustrations, and lists of figures. It should be noted that some cues can function as both navigation cues and orientation cues (i.e. bookmarks \& tabs).

\section{RELATED WORK}

The related work most pertinent to this study includes the design of pBooks and eBooks, reader expectations, and the study of reading and readers for both pBooks and eBooks.

Typically, book design refers to the design of layout, format, typography, colour, binding, shape and the numerous other elements that constitute what we consider to be a book today. The structure of the book is a complicated combination of texts, illustrations, images, and blank space (Mak 2011). Vanderschantz and Timpany (2013) attempt to classify and describe the range of design features of pBooks found in an academic library. They discuss the implications that shape, size, colour, typography and format have on the selection and use of books and they give recommendations for the design of pBooks for identifiable user groups. The presentation of a range of features including $\mathrm{ToC}$, front matter, and book covers of eBooks contained in a digital library has also been shown to impact the use and navigation of eBooks (McKay et al. 2012).
With respect to advice for the design of books Cowley and Williamson (2007) proposes that all elements within a book should be able to be easily read and used. Darnton (2009) concludes that a books' design should be pleasant and invisible unless required. Therefore, when facilitating the reading process, designers must assist readers in both comfortable reading and in the location of specific information. Thus, we highlight the importance of our study into the design of these navigation and orientation mechanisms to assist the user and reader of both pBooks and eBooks.

Research suggests that users expectations during the use of eBooks are inherited from their experience with pBooks (Chong et al. 2009). For this reason the early design of content, typography, orientation and navigation cues in eBooks has been influenced by the design of pBooks. The design of digital libraries and personal eBook libraries has also been influenced by the design of physical spaces and physical book shelves (Vanderschantz et al. 2015). Equally, eBooks are often considered an extension of pBooks (Carden 2008). To this end there have been two approaches to the design of eBooks; the first relates to design that follows the traditional book metaphor, and the second the use of design features that encompass the affordances of the electronic format. eBooks that have been designed following the traditional book metaphor (Landoni and Gibb 2000) are those that use existing design models from their counterparts, such as the table of contents, layout, and page numbers. The work of Landoni and Gibb (2000) also indicated that the visual cues users were familiar within pBooks such as headings and page numbers were favourably reviewed by users in their studies. eBooks that encompass the affordances of the electronic medium would be those that implement dynamic interaction features of the digital spectrum such as the use of hyperlinks, page scrolling, and effective or novel user interaction possible in electronic formats, but not traditional books. For this reason our investigation analyses orientation cues in both pBook and eBook formats in order to make recommendations for eBook design.

Investigations of reading, including users preferences, habits, and actions during reading have long been considered difficult (Marshall 2009). In the very early literature on this topic it was highlighted that when comparing print and electronic reading the numerous factors which influence these studies are difficult to control for (Dillon 1992). Marshall (2009) gives a thorough review of the studies of readers and reader preferences that have been performed both in the lab and in the wild through ethnographic, interview, field, and user studies. User preference for reading has been reported as has user preference 
for interacting and navigating. The limitations of eReading identified by readers and researchers alike relate to the idyllic preference of a traditional book (the smell, the feel, the tactility), reading preference (perceived eye strain, comfort or otherwise), and the interaction, navigation, skim-ability of present eBook design (e.g. Marshall and Bly 2005).

There is little specific research into the design of orientation cues for reading in either pBooks or eBooks. Related to orientation is a readers use of spatial memory during location of information and relocation of previously read or viewed information in a pBook. It is well established that when reading printed text, readers create visual or spatial memories for the location of information by identifying their physical location and position on a page or within a book (Rothkopf 1971; Lovelace and Southall 1983). These visual locations are thought to be less precise in digital environments and weaker still in scrolling interfaces (Olsen 1994; Haas 2013). Perhaps the most recent recommendation is that orientation may require both hardware and software solutions (Marshall 2009). We begin here to fill this gap with an investigation into potential visual solutions for orientation in eBook software.

\section{CASE STUDY}

We investigated the use of orientation cues when a book is published in both print and electronic format. The purpose of this study is to compare and analyse orientation cues used within physical and electronic environments. By analysing similarities and differences, design features about orientation cue in physical and electronic books can be discovered, which will assist readers to read smoothly and eBook designers to design effective orientation cues.

\subsection{Methodology}

We selected four non-fiction books (from the researchers' personal collection) that were available as both pBook and eBook. The books were assessed in their paperback printed format and in up to three common eReader applications on the iPad (Kindle, Kobo, and iBooks) depending on availability at the time of the study (see Table 1). The first book was a reference book about travel in New Zealand. The second book was an instructional book about how to visualize ideas. The third book was an educational book about how to realize your dreams. The fourth book analysed was a biography about the life of Steve Jobs.

A series of five questions on orientation cues were developed in order to analyse the four books (see

\begin{tabular}{|c|l|c|c|c|c|}
\hline & Book title & Kindle & Kobo & iBooks & pBook \\
\hline \hline 1 & $\begin{array}{l}\text { Lonely Planet: New } \\
\text { Zealand }\end{array}$ & $\mathrm{x}$ & $\mathrm{x}$ & $\mathrm{x}$ & $\mathrm{x}$ \\
\hline 2 & $\begin{array}{l}\text { Creative Visualiza- } \\
\text { tion for DUMMIES }\end{array}$ & $\mathrm{x}$ & & & $\mathrm{x}$ \\
\hline 3 & The Magic & & $\mathrm{x}$ & & $\mathrm{x}$ \\
\hline 4 & $\begin{array}{l}\text { Steve Jobs: The } \\
\text { Man Who Thought } \\
\text { Different }\end{array}$ & & & $\mathrm{x}$ & $\mathrm{x}$ \\
\hline
\end{tabular}

Table 1: Books and formats tested

\begin{tabular}{|l|l|}
\hline Q1 & $\begin{array}{l}\text { What orientation cues are given to indicate a } \\
\text { readers exact location? }\end{array}$ \\
Q2 & $\begin{array}{l}\text { What orientation cues are given to indicate a } \\
\text { readers relative location? }\end{array}$ \\
Q3 & $\begin{array}{l}\text { How does a reader know their current location? } \\
\text { Q4 }\end{array}$ \\
Where are page numbers located and what is their \\
Q5 & $\begin{array}{l}\text { Where at? } \\
\text { located and what is their format? }\end{array}$
\end{tabular}

Table 2: Analysis Questions

Table 2). These were answered for the pBook and eBook editions of our four test books.

\subsection{Case Study Results}

We compared and contrasted the way the physical object, page numbers, running headers, progress lines/bars, and tabs were presented in the two different media.

\subsubsection{Page numbers}

We found that page numbers were present in all formats of all books. We observed a number of differences: in the four pBooks the page number information consisted of only the current page number, while in all three electronic environments the current page number as well as the total number of pages (in either the chapter or the whole of the book) was provided using a "l" as a separator (i.e. $\mathrm{x} / \mathrm{y}$ ). This means that readers can tell their reading progress by comparing the current and total page numbers. In the print version of Book 4, the page number was located in the bottom right corner on the first page of each chapter (always beginning on a right page). This and the space above the chapter title that forms a white block and provides a clear contrast with the text, made it easy to locate the beginning of each chapter. While the page numbers were located at the top of each page in three of the four pBooks, they were located at the bottom of the page in all of the eBooks. pBooks 1,2 and 4 omitted page numbers on the first chapter pages, while all eBooks provided page numbers on every page.

\subsubsection{Running headers/shoulders/footers}

Information in headers, shoulders or footers may provide important orientation cues. Only the print 


\begin{tabular}{|l|c|c|c|c|c|c|}
\hline orientation cue & $e B o o k 1_{p}$ & $p B o o k 4_{p}$ & $e B o o k 2_{e}$ & $p B o o k 5_{e}$ & $e B o o k 3_{e}$ & $p B o o k 6_{p}$ \\
\hline \hline page number (chapter start) & - & - & bottom centre & bottom centre & bottom right & bottom right \\
page numbers (page right/ left) & top right/left & top right/left & bottom centre & bottom centre & bottom right & bottom right/left \\
max page number & - & - & bottom centre & bottom centre & bottom right & - \\
running header (text page) & chapter title & chapter title & book title & book title & book title & - \\
running header (chapter start) & - & - & book title & book title & book title & - \\
running footer & - & - & page numbers & page numbers & chapter title & chapter title \\
progress bar (bottom) & - & - & relative location & relative location & relative location & - \\
progress text & - & - & bottom right & bottom right & - & - \\
\hline
\end{tabular}

Table 3: Designs of orientation cues based on pBook or eBook design

edition of Book 4 did not have running headers; all other physical and digital editions had running headers or running shoulders. pBooks 2 and 3 used running headers and pBook 1 used a running shoulder to provide chapter information in physical books. In portrait orientation Kindle (Book 1 and 2) and iBook (Book 1 and 4) showed the book titles in the header. When rotated to landscape, they showed the authors name on the left page and book title on the right page. This means that running headers were used here to inform readers about the book rather than identifying the current location within the book. Kobo (Book 1 and 3) showed the current chapter information in a running footer. It appears that this orientation function for identification of location within the book when used in eBooks is not encoded in running headers but instead in running footers.

\subsubsection{Tabs}

No tabs were used in any of the eBooks in our study. The paper edition of Book 1 used printed tabs on the page edge to indicate sections, however, this orientation cue was not retained in the electronic version of Book 1.

\subsubsection{Progress bars}

In pBooks the thickness of the block of remaining pages in a book gives an indication of how far through the book the reader has progressed. In eBooks, a progress bar is a useful orientation cue to inform readers about their current location in and progress through the book. Progress bars may inform about the exact location in the book or they may give a relative location within a chapter or a section of the book.

eBooks 1, 2 and 3 (in Kindle and Kobo) had relative progress bars that informed the reader about their approximate progress or location relative to the length of the book. Books 1 and 4 in iBooks showed a progress bar and a button, which, when pressed, would identify the chapter title and current page number. Thus the progress bar in iBooks encoded both exact and relative locations within the book.

The progress bar in the Kobo was located at the top, while the location of the progress bar in Kindle and iBooks was on the bottom. Kindle also gave a percentage indication to provide relative location through a book, but the other two applications did not have this feature.

\subsubsection{Physical cues}

The physical object itself is an orientation cue only in pBooks. This orientation cue is established by the readers comparing the thickness or number of pages before or after their current location. Because eBooks lack the physicality of pages, this orientation cue is not present in an eBook. In the eBooks studied there was no visual representation of the number of pages read, or still to read, other than the progress bar or numbering of current or total pages.

\subsubsection{Further observations on eReaders}

In Kindle, page number, progress bar, and percentage were controlled by the application, while chapter heading and running header were controlled by the book itself. In Kobo, the application controlled the page number represented to the user, the table of contents, the running header, and the running footer, while the book controlled the section and chapter headings that were displayed. In iBooks, the application displayed the page number, progress bar and running header, while the book displayed the section and chapter headings. This demonstrates that in the eBook environment page numbers, progress bars and running headers (shoulder/footer) tended to be part of the eReader application, while section and chapter headings were typically part of the installed eBook itself.

\section{USER STUDY: EXPERT REVIEW}

We used a semi-structured interview with four expert users to investigate how readers are able to determine their location and reading progress in pBooks and eBooks, and which orientation cues they find most useful.

\subsection{Methodology}

We take the approach of a heuristic study (Nielsen and Molich 1990) in which a small set of expert evaluators examine interface elements in six pBook and eBook models. Note that different to traditional 
user testing, in a heuristic study the researcher may interact with the experts (e.g., answering questions) beyond the typical minimalist approach in traditional studies. Here the aim is to explore the possibilities and usefulness, not to identify usability mistakes. However, expert evaluators were only provided with information if they requested it from the researcher.

Participants. The four participants were competent readers; all were academics with well-established research expertise in either graphic design or interface/interaction and usability design.

Materials. We designed three pBook models and three eBooks models based on common pBook and eBook orientation cues identified in Section 4, see Table 3. The book designs were displayed on prepared pages within a physical book and on an iPad, respectively. The physical book chosen was similar in size and weight to the iPad. The printed book page and the iPad page were the same, both were $220 \mathrm{~mm} \times 160 \mathrm{~mm}$. In each book the same source text was used, which was taken from Book 4 explored in Section 4 (Steve Jobs: The Man Who Thought Different). Pages without images were chosen from this book and no changes were made to text content. Different portions of the book were used, all of which were sampled from the beginnings of chapters. The redesign of the selected pages focused on the orientation cues contained within the margins of the pages, not on the design of the book text. These orientation cues that were designed included running headers (footer), progress bars, percentage, page numbers and chapter headings.

Table 3 gives an overview of the orientation cues used in the six models. We refer to the three eBook designs as $e B o o k 1_{p}, e B o o k 2_{e}$ and $e B o o k 3_{e}$ and refer to the three physical book design as pBook $4_{p}$, $p B o o k 5_{e}$, and $p B o o k 6 p$. The indices $e$ and $p$ indicate the origin of the design for the orientation cue as being from either eBooks or pBooks respectively.

The design elements used in eBook $1_{p}, p B o o k 4_{p}$, pBook $6_{p}$ are based on observations of elements used in physical books found in the case study reported in Section 4. The design of eBook $2_{e}$, $p B o o k 5_{e}$ and $e B o o k 3_{e}$ are based on orientationcues found in eBooks.

eBook $2_{e}$ and $p B o o k 5 e$ follow design elements used in the iBook (e.g., running header with book title). $e B o o k 3_{e}$ uses some orientation cues used by Kindle (e.g., progress bar design) and is influenced by the Kobo design (e.g., centred running footer).

In $e B o o k 1_{e}$ and $p B o o k 4_{p}$ page numbers are located in the top left/right page border as found in all four physical books examined in the case study

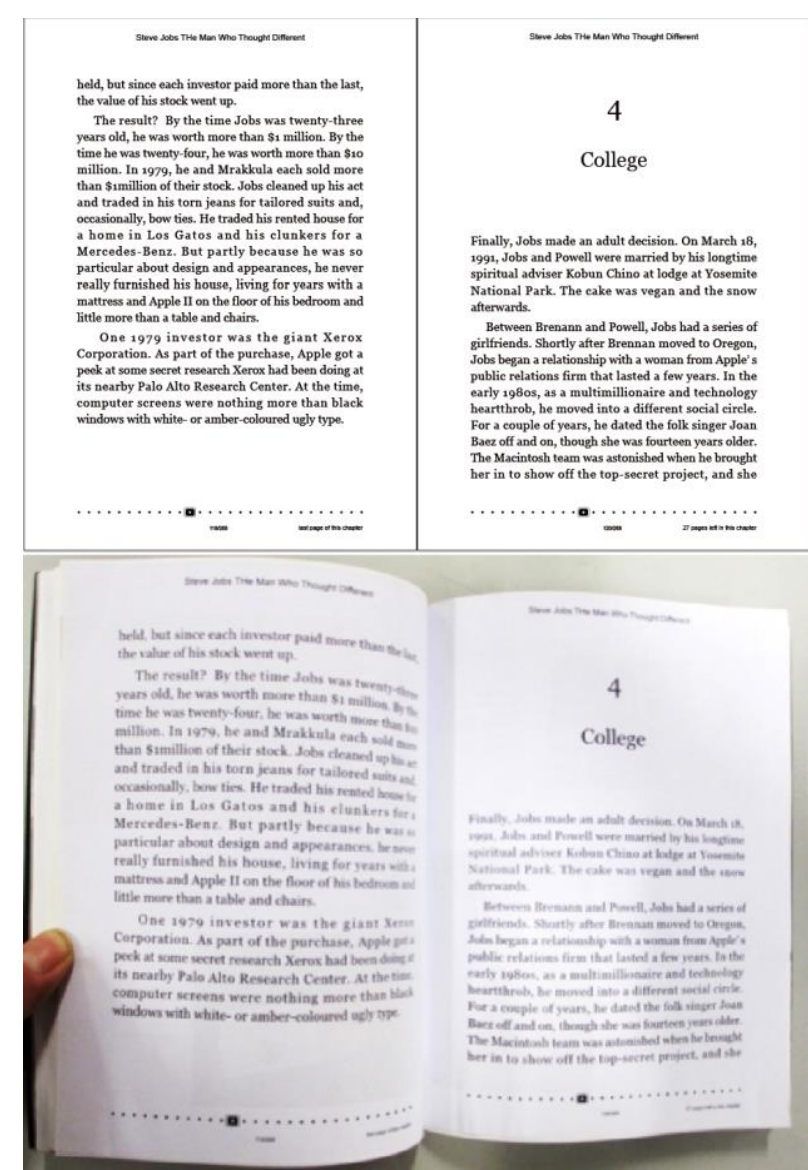

Figure 1: Design \& final pBook model for $p B o o k 5_{e}$

(reported in Section 4). They also follow the principle of omitting the page number on chapter start pages. These two book models had running headers displaying chapter titles, compared to the other book models which used running headers showing book titles. The running header with chapter information had been observed in all three eBook applications (see Section 4) and was tested in eBook $1 p$ and pBook $4_{p}$. Two styles of progress bar were used in the six books, these are shown in Figure $1\left(p B o o k 5_{e}\right)$ and Figure $2\left(e\right.$ Book $\left._{e}\right)$.

pBook6 $p$ primarily explores $\mathrm{pBook}$ orientation cues. We did not observe pBooks to use running headers with chapter titles in our case study, however this was seen in eBooks and was an alternative orientation cue that we tested with this book design.

Due to space limitations, we do not show images of each design nor the final model for the six books. Figure 1 shows the design for $p B o o k 5_{e}$ (top) and the final physical book model that was created for the same design (bottom). Figure 2 shows the eBook3e in its final form on an iPad.

Interview questions. A semi-structured interview procedure was used to gather feedback and 


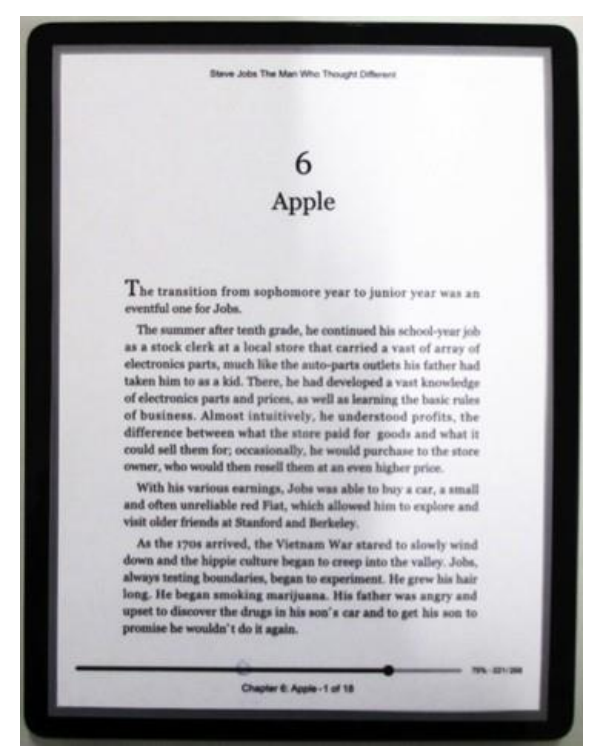

Figure 2: Final eBook model for eBook3e

recommendations from participants. Each book design model was presented one-at-a-time with participants given time to read and explore before being presented with the next. Questions 1 to 5 were asked after each book was reviewed (see questions in Table 4). After all 6 book models were seen by an expert, questions 6 to 9 were asked to explore the design space further.

\begin{tabular}{|l|l|}
\hline Q1 & $\begin{array}{l}\text { Which orientation cue did you use to know where } \\
\text { you are in each book? }\end{array}$ \\
Q2 & $\begin{array}{l}\text { Which orientation cue did you use to know your } \\
\text { reading progress in each book? }\end{array}$ \\
Q3 & $\begin{array}{l}\text { How do you know which chapter you are in? } \\
\text { How do you know which book you are reading? }\end{array}$ \\
Q5 & $\begin{array}{l}\text { Which orientation cue do you think works better for } \\
\text { a print book and an eBook? }\end{array}$ \\
\hline Q6 & $\begin{array}{l}\text { Which design style (based on print book or eBook } \\
\text { design) do you feel is most effective at telling you } \\
\text { where you are? }\end{array}$ \\
Q7 & $\begin{array}{l}\text { Which orientation cue do you feel is most effective } \\
\text { at telling you where you are? }\end{array}$ \\
Q8 & $\begin{array}{l}\text { Which orientation cue do you feel is more useful for } \\
\text { you to determine your reading progress? }\end{array}$ \\
Q9 & $\begin{array}{l}\text { In what kind of situation would you want to know } \\
\text { where you are in this book? }\end{array}$ \\
\hline
\end{tabular}

Table 4: Interview Questions

\subsection{User Study Results}

Here we outline the results of our semi-structured interviews. Note that participants were not provided prompts or pre-defined cues for answering these questions. Instead the participants gave open responses to the questions in Table 4 . Where required, a participant was asked to expand their answer with an opportunity to explain their thinking. For ease of comparison, each of our graphs shows all responses along the $\mathrm{x}$-axis that the four participants mentioned throughout the study. This means that some cues are present on the $x$-axis of a bar chart even if they were not discussed by any participant in relation to that question.

Q1 (location cues used). Figure 3 shows an aggregation of the orientation cues the four participants' mentioned/used to determine their current location in each of the six book models. Note that not all orientation cues were available in each book model (see Table 3 for cues that were present). The only orientation cue used in eBook $1_{p}$ was the chapter heading, which was also used most in $p B o o k 4_{p}$ in addition to other cues. In eBook $2_{e}$, $e B o o k 3 e$ and $p B o o k 4_{e}$ the most used cue was the progress bar. In $p$ Book 6 , none of the cues were used by all participants. Overall, the chapter heading and the progress bar were most often used, more often than the characteristics of the physical object, i.e., comparing the thickness or number of pages before or after their current location to determine the relative location in the pBook.

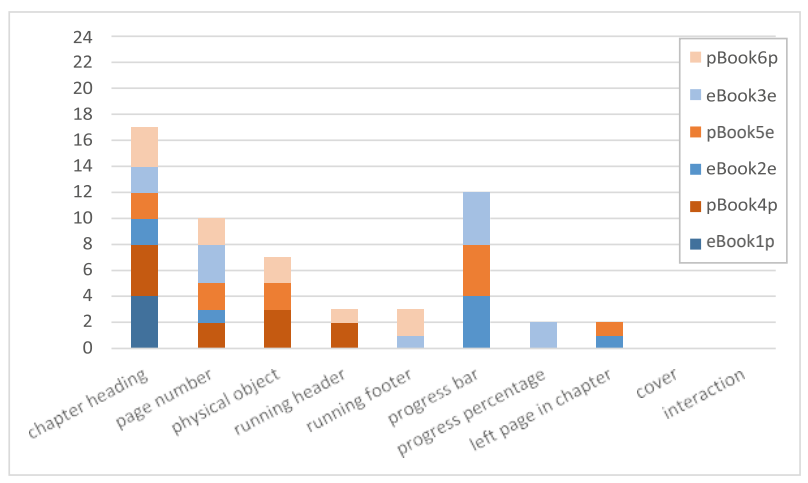

Figure 3: Location cues used in books (Q1)

Q2: (reading progress cues used). Figure 4 shows an aggregation of the four participants' use of orientation cues to determine their reading progress in each of the six book models. The only orientation cue used in eBookl $p$ was the chapter heading, although page numbers were also provided (but not used). In the pBook model $p B o o k 4_{p}$ with the same design as the eBook model $e B o o k 1_{p}$, page numbers were used. In $p B o o k{ }_{p} p$ the physical object was used more than the cues within the book (chapter heading and page numbers). For eBook $2_{e}$, we found that page numbers were used by three of the participants. In the comparably designed pBook $p B o o k 5_{e}$ all participants used the page numbers. In pBook $5_{e}$ and $e B o o k 2_{e}$ the most used cue was the progress bar, used by all participants. For $e B o o k 3_{e}$ and $p B o o k 6_{p}$ a variety of cues were used, but none of these were used by all participants.

Q3: (chapter cues used). Figure 5 shows an aggregation of the four participants' use of orientation cues to determine their current chapter in each of the six book models. The chapter heading 


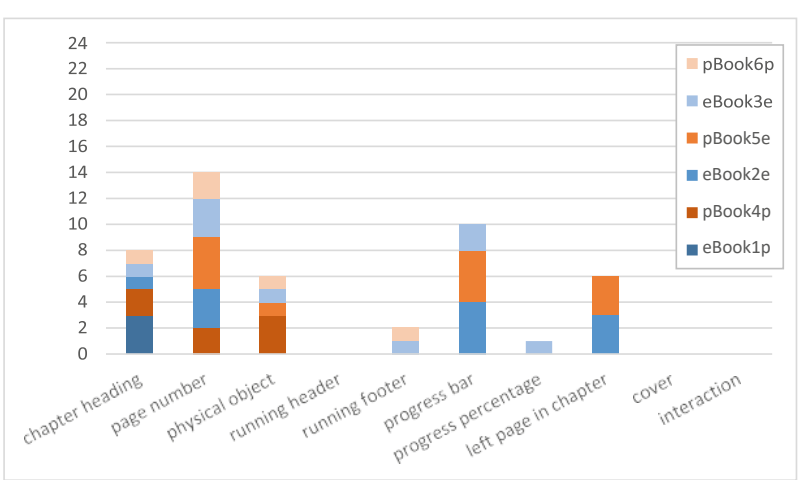

Figure 4: Reading progress cues used in books (Q2)

was the cue that almost all participants used; it was additionally available in the running header $\left(e B o o k 1_{p}, p B o o k 4_{p}\right)$ or footer $\left(e B o o k 3_{e}, p B o o k 6_{p}\right)$, respectively. Only one participant mentioned using the running header in the physical book pBook $4 p$, while for the identical digital design in $e B o o k_{p}$, three participants mentioned the running header.

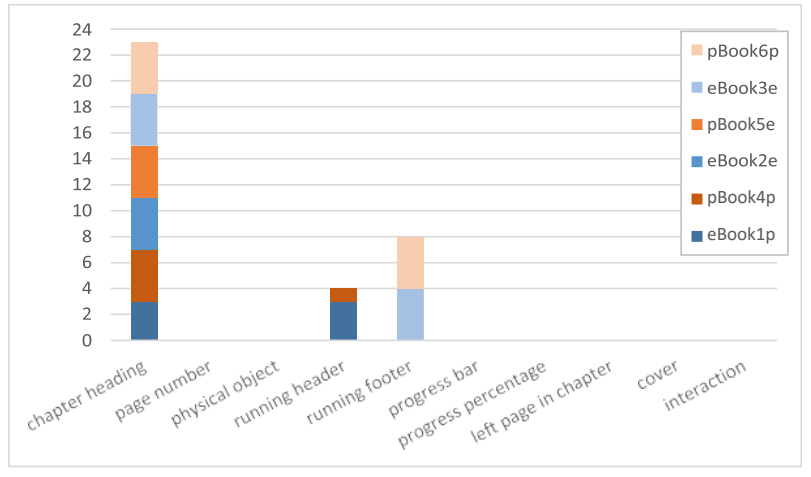

Figure 5: Chapter cues used (Q3)

Q4: (book identity). Figure 6 shows an aggregation of the four participants' use of orientation cues to determine which book they are seeing. For books eBook $2_{e}, p B o o k 5_{e}$ and eBook $3_{e}$, participants 2, 3, and 4 used the running header (containing the book title). In the cases where the explicit information was missing from the presented pages, other options were explored. Participants turned to the cover for pBooks, and for eBooks participants tried interacting with the eBook (i.e., pressing the screen) to obtain the information. One participant was unable to answer this question for $e B o o k 1 p$.

Q5: (preference for orientation cues - print vs eBook). Figure 7 shows an aggregation of the four participants' who stated their preferences on which orientation cues work better for pBooks and eBooks, based on the six book models they had used. Where available, the progress bar was seen as particularly useful, however, more so for eBooks than for pBooks. The running header was only mentioned for pBooks even though it was also available in

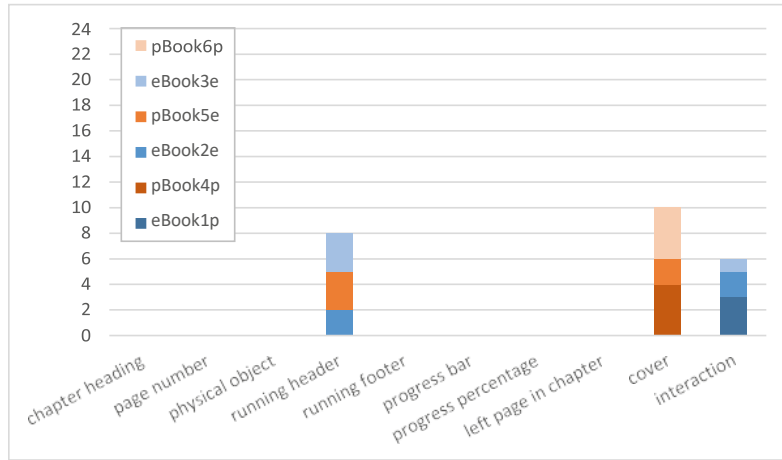

Figure 6: Cues used for book identity (Q4)

eBook models. Chapter headings were mentioned several times for both eBook $1_{p}$ and $p B o o k 4_{p}$, but hardly any other book models. The running footer, was preferred for $p B o o k 6 p$ over the progress bar, while for $e B o o k 3 e$ the preference was reversed.

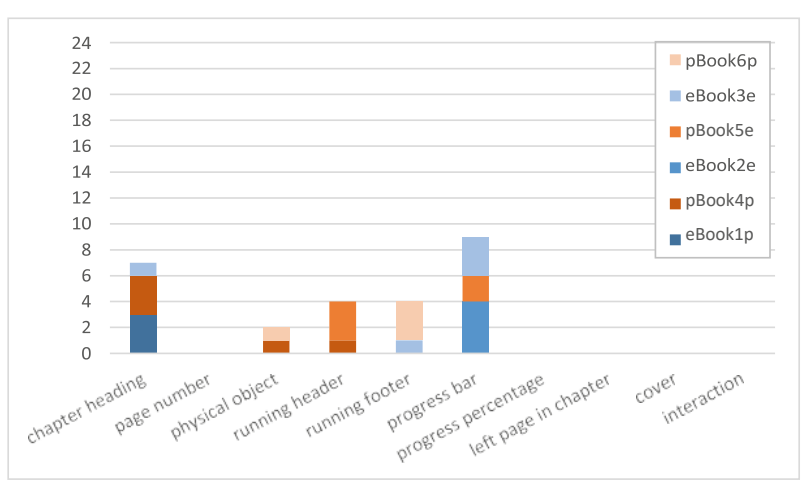

Figure 7: Cues for print vs eBook (Q5)

Q6: (preferred model-for orientation in book). This question gave participants the opportunity to choose one book model (from any of the six models) that they thought was most effective at determining where they were in books. Participants 1 and 2 believed the orientation cues in $e B o o k 3 e$ to be most effective, whereas Participants 3 and 4 believed the cues in $e B o o k 2_{e}$ to be most effective. It is interesting that the corresponding pBooks (e.g., pBook5e) were not selected. We also observe that $e B o o k 2 e$ is the eBook in which all four participants agreed that the progress bar is a preferred orientation cue, while for $e B o o k 3_{e}$ three participants prefer the progress bar. That is, the preferred books seem to be the two eBooks with progress bars.

Q7: (preferred cue - for location in book). This question asked participants which specific orientation cue they believed was the most effective at telling the reading location. Participant 1 believed that for physical books, the characteristics of the object itself (thickness of pages) was the most effective cue for telling location, while chapter heading and progress bar were more effective at 
distinguishing location in eBooks. Both participants 2 and 4 thought the progress bar was the most effective at telling location in both pBooks and eBooks. Participant 3 believed that for both the pBook and eBook models, page number and chapter number were most effective at telling location.

Q8: (most useful cue - for reading progress). This question asked about the most useful cue for telling reading progress. Participants 1 and 3 thought that the physical object cue (thickness of pages) was the most useful orientation cue for determining reading progress. Participant 1 believed that for electronic books the progress bar was the most useful. Both Participants 2 and 4 also preferred the progress bar for both the pBook and eBook. Furthermore, Participant 1 explained that even though a percentage cue may tell the reading progress, it does not allow the user to navigate to the exact location in the book.

Participant 3 argued that for electronic books there were no proper orientation cues to indicate the reading progress. They explained that, for example, if a reader jumps from the end of chapter 1 to the beginning of chapter 3 in an eBook, the progress bar will show that chapter 2 was finished even if in reality it was skipped.

Q9: (situations for book location). This question was an open question that aimed to discover specific situations in which participants would want to know their location when reading books.

Participant 1 said that when reading physical books, he might forget to use a bookmark and later want to know the location of specific material. In these cases he described that he usually refers to pictures or other features to remind himself. For the eBooks, he was more concerned about his reading progress rather than his location because he said that could highlight the material he wanted to recall, or he could use the search function to find it.

Participant 2 discussed using orientation cues to find out about reading progress or what proportion of the book or chapter was completed. He also wanted to know the progress in terms of how far he was from the end of a chapter, or the end of the whole book, so that he could decide whether or not they should continue reading now or postpone. Similarly, Participant 3 said that in an interesting book, such as a detective novel, they would sometimes like to know how far they need to continue reading to reach a solution. Moreover, when reading at night, they would want to know how long the current chapter was, so they could plan a break. Participant 4 said that they only wanted to know their location in a book just before finishing reading.
Furthermore, the participants liked to know the parts of the book they had already read, so that they could find out if they had missed any part, section, or pages of the book. This reinforces the need for page based orientation cues that link to book based orientation and navigation cues such as the table of contents.

\section{DISCUSSION}

As was noted in the related work discussion (see Section 2), very few investigations into orientation cues for reading in either pBooks or eBooks have been published which we may compare to our own studies reported here. This paper therefore begins to fill this gap regarding readers' needs for orientation mechanisms in both physical and electronic books.

\subsection{Aggregation of Findings}

The findings of our studies highlight the need for further investigations regarding the design of orientation and navigation cues for readers in both pBooks and eBooks. Our explorative investigations reported in this paper show that chapter headings, page numbers, and progress bars may be the most useful visual orientation cues for readers when orienting themselves in both pBooks and eBooks. These three features were commonly discussed by the experts in our heuristic study and while their specific usage may differ in the electronic or physical reading environments, use of similar designs across pBooks and eBooks may prove useful to readers.

We note that orientation cues to determine the current location (Q1) and cues to determine reading progress are different (Q2): While for the former, a clear preference for the progress bar was observed, the picture is more nuanced for results of Q2 because our small sample of users did not appear to use the same cues to solve this problem. Use of chapter headings was positively discussed by the four expert participants for both identifying locations within a book and for determining reading progress. Chapter headings assisted with determining location in a book, identifying the chapter currently being read, and confirming reading progress. Running headers (containing book or chapter information) were used to identify the book and the current chapter being read. Integration of chapter headings as a part of running headers or footers, which are constantly available to the reader (not the current norm in eReading applications, see Section 4) will likely assist readers with orientation. These observations support the recommendation of Bernstein (1988) who suggested that orientation cues for hypertext documents should be prominently displayed in predictable and persistent locations in order to decrease potential for reader disorientation. 
The work of Landoni and Gibb (2000) also indicated that the visual cues users were familiar with in pBooks (such as headings and page numbers) were favoured by users in their studies with eBooks.

Our review by experts has confirmed that page numbers are a useful tool for identifying location within a book and for determining progress during reading. Therefore, page numbers form an important consideration during the development of pBooks and eBooks alike. Page numbers in pBooks have traditionally been a number identifying the current page, while in eBooks it is common to use both the information about current page and total pages (often represented as $\mathrm{x} / \mathrm{y}$ ). This additional information of total page numbers may assist readers with being informed about their reading progress and deserves further investigation in pBooks and eBooks.

The difficulty regarding page numbers in an electronic environment, however, is made more complex by readers being able to resize texts for personal reading preferences. Should a reader resize text after beginning to read a text any use of page numbers as an orientation cue to this point becomes problematic. This is because the original page number may not match the re-flowed page number. Additionally, if a reader quotes or references information from a particular page in a text this may result in page numbers being incongruent for future readers. Presently some eReading applications solve this with what the Amazon Kindle refers to as location numbers, which can be mapped to page numbers if required. Resolving page number discrepancies provides an interesting design challenge for future work.

Progress bars, while a common feature of eBooks today, may prove to be useful for readers in traditional pBooks; they were generally positively received when used in pBooks in our study. Progress bars were used by expert participants to assist with determining both location and reading progress. Progress bars are currently treated differently by many eReader manufacturers. Further investigations of the information affordances of different design styles of progress bars may provide additional insights. We recommend progress bars as a tool that provides an electronic alternative to the muchmaligned physical object cue discussed in the literature (e.g. Wilson et al. 2002).

We discussed reading situations for which the four experts felt orientation cues would be helpful. Participants named aspects of re-finding (both of information and particular pages) as well as reading progress (how much between their current place and the end of the chapter or book) and identification of missed pages or sections. These findings open up new avenues for the use of orientation cues beyond the situation of ongoing searching or reading (assumed throughout the study). This strengthens our argument for deeper exploration into how orientation cues support people reading in a variety of situations and book genres.

\subsection{Limitations \& Future Work}

We acknowledge that such exploratory studies as the ones reported here are inevitably limited in terms of generalisability. The most notable limitations of our study are the use of one text genre and a small sample size. We used only non-fiction books in this investigation as there is evidence that readers interact with genres of texts differently depending on the type of information the reader is looking for or the reading situation (O'Hara 1996). Further work on orientation cues is required to review if differentiation based on reading material type is required.

As we have argued before, the literature in this area is sparse and our exploratory investigation only begins to review the current state of pBook and eBook orientation cue design. Our case study informs the development of future studies and covered only a small number of pBook and eBook formats. Our user study took the approach of a heuristic study (Nielsen and Molich 1990) with expert users. We based our sample size of participants for our study on the recommendations of Nielsen and Molich (1990) who suggest that 3 to 5 participants will suffice in a study of this nature.

Future work in this area should investigate what orientation cues users prefer and require for different reading types and needs across both fiction and nonfiction. These are planned to be tested with larger sample sizes and studies that explore both preference and efficacy.

\section{CONCLUSIONS}

This paper reviewed current designs for orientation cues in physical books (pBooks) and electronic books (eBooks) and reported an initial exploration into the effectiveness of these orientation cues for pBooks and eBooks.

Our case study explored four texts available in both pBook and eBook editions to investigate similarities and differences in orientation cues. We identified that all physical book editions as well as the Kindle, Kobo, and iBooks editions used similar orientation cues for current location and reading progress (page numbers, chapter headings and section headings). However, relative location was found to use different cues in different situations. Furthermore, we noted 
that reading progress in pBooks may use the physical object, whereas eBooks typically employ a progress bar. Some orientation cues, such as page numbers, running headers (shoulders/footers), tabs, and progress lines/bars were always available in eBooks, whereas others, such as chapter headings, section headings, and section title pages are only sometimes available. In comparing Kindle, Kobo, and iBooks it was evident that the applications controlled most of the orientation cues, such as page number, table of contents, progress bar, and running headers and footers, whereas only a limited number of orientation cues, such as section and chapter headings, were controlled by the eBookitself.

Our heuristic study involved four expert participants investigating orientation cues in six pBook and eBook models. We found that for the physical book models, chapter headings were the most frequently used orientation cue. Page numbers were the second-most frequently chosen orientation cue, followed by the physical object. Finally running headers were also used and discussed by our experts as being useful, but were a less frequently used orientation cue in pBooks. Conversely, for the electronic book models, chapter headings were the most-favoured orientation cue. Progress bars were the second most popular orientation cue discussed by our experts for eBooks. Finally, page numbers were used less frequently in electronic books that physical books.

In designing pBooks and eBooks, orientation cues remain essential features to determine absolute and relative location. A number of possible future studies and directions have been discussed, including fiction books, larger-scale studies, and exploration of reading situations.

\section{REFERENCES}

Bernstein, M. (1988). The bookmark and the compass: orientation tools for hypertext users. SIGOIS Bull., 9(4):34-45.

Carden, M. T. (2008). E-books are not books. In Proceedings of the 2008 ACM workshop on Research advances in large digital book repositories, pages 9-12. ACM.

Chong, P. F., Lim, Y. P., and Ling, S. W. (2009). On the design preferences for ebooks. IETE Technical Review, 26(3):213-222.

Cowley, D. and Williamson, C. (2007). The world of the book, volume 93. The Miegunyah Press.

Darnton, R. (2009). The case for books: Past, present, and future. PublicAffairs.
Dillon, A. (1992). Reading from paper versus screens: A critical review of the empirical literature. Ergonomics, 35(10):1297-1326.

Haas, C. (2013). Writing technology: Studies on the materiality of literacy. Routledge.

Landoni, M. and Gibb, F. (2000). The role of visual rhetoric in the design and production of electronic books: the visual book. The electronic library, 18(3):190-201.

Lovelace, E. A. and Southall, S. D. (1983). Memory for words in prose and their locations on the page. Memory \& Cognition, 11(5):429-434.

Mak, B. (2011). How the page matters. University of Toronto Press.

Marshall, C. C. (2009). Reading and writing the electronic book. Synthesis lectures on information concepts, retrieval, and services, 1(1):1-185.

Marshall, C. C. and Bly, S. (2005). Turning the page on navigation. In Proceedings of the 5th ACM/IEEE-CS joint conference on Digital libraries, pages 225-234. ACM.

McKay, D., Hinze, A., Heese, R., Vanderschantz, N., Timpany, C., and Cunningham, S. J. (2012). An exploration of ebook selection behavior in academic library collections. In International Conference on Theory and Practice of Digital Libraries, pages 13-24. Springer.

Nielsen, J. and Molich, R. (1990). Heuristic evaluation of user interfaces. In Proceedings of the SIGCHI conference on Human factors in computing systems, pages 249-256. ACM.

O'Hara, K. (1996). Towards a typology of reading goals. Rank Xerox Research Centre Technical Report EPC- 1996-107.

Olsen, J. (1994). Electronic journal literature: implications for scholars. Meckler Corporation.

Rothkopf, E. Z. (1971). Incidental memory for location of information in text. Journal of verbal learning and verbal behavior, 10(6):608-613.

Vanderschantz, N. and Timpany, C. (2013). Who says you can't judge a book by its cover? International Journal Of The Book, 10(4).

Vanderschantz, N., Timpany, C., and Hinze, A. (2015). Design exploration of ebook interfaces for personal digital libraries on tablet devices. In Proceedings of the 15th New Zealand Conference on Human-Computer Interaction, pages 21-30. ACM.

Wilson, R., Landoni, M., and Gibb, F. (2002). Ausercentred approach to e-book design. The Electronic Library, 20(4):322-330. 